\title{
Penerapan Metode Bottom-Up Untuk Mendasin Ulang Database Pada Sistem Informasi Perhotelan Front Office InspiredHMS
}

\author{
Salvinia Natans ${ }^{1 *}$, Irmayansyah ${ }^{2}$ \\ ${ }^{1}$ STIKOM Binaniaga/Sistem Informasi \\ Email: s_natans90@gmail.com \\ ${ }^{2}$ STIKOM Binaniaga/Sistem Informasi \\ Email: irma@stikombinaniaga.ac.id
}

\begin{abstract}
In the front office InspiredHMS hotel information system, front office officers must make a lot of price codes (ratecode) with almost the same name for each particular period. This is because the price code will be different when low season, high season and peak season. The purpose of this study is to make a price code (ratecode) but have different prices in a certain period and redesign the database so that there is no need to manually select ratecode according to the date of reservation using the bottom-up method. The bottom up method is an approach to designing a database that starts from attributes (i.e. properties of entities and relationships), through analysis of associations between attributes, grouped into relationships that represent the types of entities and relationships between entities. To test the efficiency of the design that results in a test by comparing the table in the database before being redesigned and the table in the database after being redesigned, from the test the efficiency percentage for the use of data space is $158.33 \%$, total records $33.98 \%$ and total usage space of $19.35 \%$.
\end{abstract}

Keywords: database, database redesign, tables, bottom up, efficiency

\begin{abstract}
ABSTRAK
Dalam sistem informasi perhotelan front office InspiredHMS, petugas front office harus membuat banyak kode harga (ratecode) dengan nama yang hampir sama untuk setiap periode tertentu.Hal tersebut disebabkan karena kode harga akan berbeda ketika low season, high season, dan peak season. Tujuan dilakukannya penelitian ini adalah membuat satu kode harga (ratecode) namun memiliki harga yang berbeda dalam periode tertentu dan mendesain ulang database agar tidak perlu melakukan pemilihan ratecode secara manual sesuai dengan tanggal reservasi dengan menggunakan metode bottom-up. Metode bottom up merupakan suatu pendekatan untuk mendesain sebuah database yang dimulai dari atribut (yaitu properti dari entitas dan relationship), melalui analisis dari asosiasi antar atribut, dikelompokkan menjadi hubungan yang memrepresentasikan jenis-jenis entitas dan hubungan antar entitas. Untuk menguji efisiensi dari rancangan yang hasilkan dilakukan uji dengan membandingkan tabel pada database sebelum didesain ulang dan tabel pada database setelah didesain ulang, dari uji tersebut diperoleh prosentase efisiensi untuk penggunaan ruang data sebesar 158,33\%, jumlah record 33,98\% dan total penggunaan ruang sebesar 19,35\%.
\end{abstract}

Kata Kunci: database, desain ulang database, tabel, bottom up, efisiensi 


\section{PENDAHULUAN}

\section{Latar Belakang}

Industri perhotelan adalah usaha penyediaan perlengakapan tempat tinggal sementara, makanan dan pelayanan lain yang diperlukan. Tujuan utama setiap hotel adalah menjual jasa kamar dengan berusaha menaikkan persentase tingkat hunian kamar hotel. Penjualan tersebut ditandai dengan penggunaan tarif sewa kamar yang tepat kepada para pemakai jasa kamar hotel. Penetapan strategi yang tepat oleh manejemen, akan berpengaruh dalam merebut persaingan pangsa pasar yang kompetif. Salah satu strategi yang bisa diambil manejemen adalah dalam menetapkan tarif sewa kamar yang sesuai, sehingga dapat menutup biaya produksi dan menghasilkan keuntungan bagi perusahaan. Ada beberapa cara dalam menetapkan harga jual / tarif sewa kamar tersebut, salah satu alat yang dapat digunakan dalam pengambilan keputusan untuk menentukan harga sewa kamar hotel yaitu dengan sistem perhotelan front office.

Dalam sistem informasi perhotelan front office InspiredHMS, pengguna harus membuat rate terlebih dahulu sebelum bisa membuat reservasi, permasalahan muncul ketika hotel mempunyai kode harga (ratecode) yang sama tetapi mempunyai harga yang berbeda untuk periode tertentu. Contohya kode harga promo akan berbeda ketika low season, high season, dan peak season. Permasalahan ini sering membuat petugas front office harus memilih ratecode secara manual untuk pengambilan harga yang tepat berdasarkan periode penyewa kamar menginap oleh karena itu diperlukan desain ulang database pada sistem front office InspiredHMS. Tabel 1 sampai dengan 3 merupakan deskripsi tabel yang terdapat pada database sistem front office inspired.

A. Nama Tabel : RM15_RateMaster

Pada tabel ini, disimpan informasi tentang Rate Code master yang isinya menyimpan masa berlakunya harga kamar.

Tabel 1.RM15_RateMaster

\begin{tabular}{r|l|lrl} 
No & \multicolumn{1}{|c|}{ Nama } & \multicolumn{1}{c}{ Tipe } & \multicolumn{1}{c}{ Ukuran } & \multicolumn{1}{c}{ Deskripsi } \\
\hline 1 & RateCode & nvarchar & 255 & Informasi kode harga \\
2 & RateDescription & nvarchar & 50 & Informasi lebth detil tentang kode harga \\
3 & StartDate & datetime & & Tanggal Mulai berlakunya kode harga \\
4 & EndDate & datetime & Tanggal Habis berlakinya kode harga \\
\hline 5 & RateID & int & Primary Key \\
\hline 6 & Deactivate & bit & Menentukan sta tus bisa digunakan atau tidak \\
7 & Weekend & bit & Menentulkan apalah rate ini memiliki harga \\
8 & Dayl & smallint & berbeda letika akhir pekan \\
9 & Day2 & smatlint & Konfigurasi hari pertama akkir pekan \\
\hline
\end{tabular}

B. Nama Tabel : RM15_RateMasterSub

Pada tabel 2 disimpan informasi tentang rate code yang lebih detail, yaitu harga kamar berdasarkan banyaknya tamu yang menginap.

C. Nama Tabel : RM15_RateBase

Pada tabel 3, berisi tentang informasi macam-macam tipe biaya yang akan dikenakan kepada tamu hotel. 
Tabel 2. RM15_RateMasterSub

\begin{tabular}{|c|c|c|c|c|}
\hline No & Nama & Tipe & Ukuran & Deskripsi \\
\hline 1 & RateID & int & & Primary Key \\
\hline 2 & ReomCat & nvarchar & 15 & Konfigurasi kategori kamar \\
\hline 3 & RoomType & nvarchar & 10 & Konfigurasi tipe kamar \\
\hline 4 & TransCode & nvarchar & 10 & Tanggal Hab is berlakunya hode harga \\
\hline 5 & Basis & smallint & & Informasi cara memasang harga \\
\hline 6 & Rate I & money & & Harga Kamar untuk 1 crang dewasa \\
\hline 7 & Rate2 & money & & Harga Kamar untuk: 2 orang dewasa \\
\hline 8 & Rate3 & money & & Harga Kamar untuk: 3 orang dewasa \\
\hline 9 & Rate4 & money & & Harga Kamar untuk 4 orang dewasa \\
\hline 10 & Rate5 & money & & Harga Kamar untuk 5 orang dewasa \\
\hline 11 & Rate6 & money & & Harga Kamar untuk 6 crang dewasa \\
\hline 12 & Rate 7 & money & & Harga Kamar untuk 7 crang dewasa \\
\hline 13 & Rate 8 & money & & Harga Kamar untuk 8 orang dewasa \\
\hline 14 & Rate9 & money & & Harga Kamar untuk 9 crang dewasa \\
\hline 15 & Rate 10 & money & & Harga Kamar untuk 10 crang dewasa \\
\hline 16 & CRatel & real & & Harga Kamar untuk 1 anak kecil \\
\hline 17 & CRate2 & real & & Harga Kamar untuk 2 anak kecil \\
\hline 18 & CRate3 & real & & Harga Kamar untuk 3 anak kecil \\
\hline 19 & CRate4 & real & & Harga Kamar untuk 4 anak kecil \\
\hline 20 & CRate5 & real & & Harga Kamar untuk 5 anak kecil \\
\hline 21 & CRate6 & real & & Harga Kamar untuk 6 anak kecil \\
\hline 22 & CRate7 & real & & Harga Kamar untuk 7 anak kecil \\
\hline 23 & CRate8 & real & & Harga Kamar untuk: 8 anak kecil \\
\hline 24 & CRate9 & real & & Harga Kamar untuk 9 anak kecil \\
\hline 25 & CRate10 & res1 & & Harga Kamar untuk 10 anak kecil \\
\hline 26 & WRatel & money & & $\begin{array}{l}\text { Harga Kamar untuk I crang dewasa ketika } \\
\text { weekend }\end{array}$ \\
\hline 27 & WRate2 & money & & $\begin{array}{l}\text { Harga Kamar untuk } 2 \text { orang dewasa ketika } \\
\text { weekend }\end{array}$ \\
\hline 28 & WRate3 & money & & $\begin{array}{l}\text { Harga Kamar untuk } 3 \text { orang dewasa ketika } \\
\text { weekend }\end{array}$ \\
\hline 29 & WRate4 & money & & $\begin{array}{l}\text { Har ga Kamar untuk } 4 \text { orang dewasa ketika } \\
\text { weekend }\end{array}$ \\
\hline 30 & WRate5 & money & & $\begin{array}{l}\text { Harga Kamar untuk } 5 \text { orang dewasa ketika } \\
\text { weekend }\end{array}$ \\
\hline 31 & WRate6 & money & & $\begin{array}{l}\text { Har ga Kamar untuk } 6 \text { orang dewasa ketika } \\
\text { weekend }\end{array}$ \\
\hline 32 & WRate? & money & & $\begin{array}{l}\text { Harga Kamar untuk } 7 \text { orang dewasa ketika } \\
\text { weekend }\end{array}$ \\
\hline 33 & WRate8 & money & & $\begin{array}{l}\text { Harga Kamar untuk } 8 \text { orang dewasa ketika } \\
\text { weekend }\end{array}$ \\
\hline 34 & WRate9 & money & & $\begin{array}{l}\text { Harga Kamar untuk } 9 \text { crang dewasa ketika } \\
\text { weekend }\end{array}$ \\
\hline 35 & WRate10 & money & & $\begin{array}{l}\text { Har ga Kamar untuk } 10 \text { orang dewasa ketika } \\
\text { weekend }\end{array}$ \\
\hline
\end{tabular}

Tebel 3. RM15_RateBase

\begin{tabular}{rrc|rl}
\hline No & Nama & Tipe & Ukuran & Deskripsi \\
\hline 1 & RBCode & smallint & & Primary Key \\
\hline 2 & RBDescription & nvarchar & 50 & Informasi tentang cara memasang harga \\
\hline
\end{tabular}

Desain ulang database pada sistem front office InspiredHMS akan dilakukan dengan menggunakan metode bottom-up. Menurut Connolly dan Begg (2002, p279). Ada 2 pendekatan untuk mendesain sebuah basis data, yaitu:

A. Pendekatan bottom-up, dimulai pada tingkat awal dari atribut (yaitu, properti dari entitas dan relationship), melalui analisis dari asosiasi antar atribut, dikelompokkan menjadi hubungan yang merepresentasikan jenis-jenis entitas dan hubungan antar entitas. Pendekatan ini cocok untuk mendesain basis data yang sederhana dengan jumlah atribut yang tidak banyak. 
B. Pendekatan top-down, digunakan pada basis data yang lebih kompleks. Dimulai dengan pengembangan dari model data yang mengandung beberapa entitas dan hubungan tingkat tinggi, kemudian menggunakan perbaikan top-down berturut-turut untuk mengindentifikasikan entitas, hubungan dan atribut berkaitasn tingkat rendah. Pendekatan ini biasanya digambarkan melalui ER (Entity Relationship).

\section{METODE}

Secara garis besar metode yang digunakan dalam penelitian ini adalah metode eksperimen, yaitu penelitian yang menerapakan sistem trial and error hingga mendapatkan spesifikasi produk dengan desain dan fungsi yang diharapkan.

\section{A. Prosedur Pengembangan}

Prosedur pengembangan merupakan langkah-langkah dari proses pengembangan yang dilakukan. Prosedur pengembangan yang dilakukan dalam pengembangan ini mengikuti tahapan-tahapan DDLC (Database Development Life Cycle), yang terdiri atas tahapan :

1. Planning, Meninjau rencana bisnis jangka panjang organisasi; berencana secara khusus untuk sistem data.

2. Feasibility Study, Mempelajari keadaan, memperkirakan biaya dan mengeksplorasi manfaat.

3. Requirements Definition, Mendefinisikan obyek bisnis dan hubungan; data dokumen persyaratan.

4. Design, Pemodelan data lengkap, desain pada tingkat konseptual, logika, dan fisik.

5. Implementation and Deployment, Desain fisik lengkap dan struktur data dan hubungan relasi antar table menggunakan DBMS, mengisi sistem data, mendapatkan sistem data siap aplikasi.

6. Maintenance and Growth, Melakukan pemeliharaan, merencanakan dan mengelola pertumbuhan sistem data

\section{B. Teknik Analisa Data}

Menurut Calero, Piatiini, Pascual, dan Serrano (2001) kualitas multidimensional pada data dapat diuji dengan matrik yang diujikan pada tabel dan skema berdasarkan jumlah field, jumlah foreign key pada tabel-tabel tersebut. Menurut Pauljah Ponniah (2001, p248) prosentase efisiensi akan membuktikan bahwa tabel mana yang lebih efektif dengan rumus prosentase kenaikan yaitu:

$$
\text { Prosentase kenaikan }=(\text { data lama }- \text { data baru }) / \text { data baru } * 100)
$$

Dimana prosentase efisiensi ini akan dibuktikan pada total panjang record, total jumlah record dan total keseluruhan byte, antara tabel pada database sebelum didesain ulang dan tabel pada database setelah didesain ulang.

\section{HASIL DAN PEMBAHASAN}

\section{Hasil}

Dilihat dari tabel yang digunakan untuk menyimpan konfigurasi rate code pada database sistem lama, ditemukan permasalahan untuk menyimpan satu rate code yang memiliki banyak rate untuk beberapa rate season yang memiliki harga yang berbeda-beda, sesuai dengan tanggal yang diinginkan. Adapun langkah-langkah pengembangan database yang dilakukan mengikuti tahapan-tahapan DDLC (Database Development Life Cycle), yang dikemukakan Paulraj Ponniah (2007, hal.32) : 
A. Database Development Life Cycle (DDLC)

1. Planning

Dengan adanya pembuatan satu rate code yang bisa memiliki banyak rate season, pengguna aplikasi dapat menaikan harga penjualan kamar yang lebih dinamis berdasarkan periode tertentu dan pengguna aplikasi tidak perlu lagi melakukan pengecekan pada reservasi yang menggunakan rate code dimana masa berlakunya sudah habis berdasarkan tanggal reservasi tamu hotel.

2. Feasibility Study

Manfaat yang didapat setelah dilakukannya desain ulang pada database diantaranya sebagai berikut :

a. Manfaat Teoritis: memberikan sumbangan penerapan metode bottom-up dalam mendesain ulang database.

b. Manfaat Praktis : memudahkan pengguna aplikasi, sehingga mereka tidak lagi melakukan pemilihan harga kamar secara manual.

c. Manfaat Kebijakan : pengguna hanya perlu membuat satu kode harga yang memiliki harga kamar berbeda-beda sesuai dengan periode tertentu sehingga pengguna aplikasi tidak lagi melakukan pemilihan harga kamar secara manual.

3. Requirments Definition

Dibutuhkannya pengembangan database yang dapat mencangkup kebutuhan bisnis pada modul Front Office InspiredHMS yang dapat mengakomodir pembuatan satu ratecode tetapi memiliki banyak rate season yang mempunyai perbedaan tanggal dan harga sesuai dengan keinginan pengguna. Berdasarkan fakta tersebut, diperlukannya untuk mendesain ulang table pada database yang menyimpan data ratecode.

4. Design

Pada tahan ini, penulis menggunakan metode bottom-up dimulai pada tingkat awal dari atribut (yaitu, properti dari entitas dan relationship), melalui analisis dari asosiasi antar atribut, dikelompokkan menjadi hubungan yang merepresentasikan jenis-jenis entitas dan hubungan antar entitas untuk melakukan desain ulang pada database.

a. Skema Konseptual

Tujuan dari tahap ini adalah untuk menghasilkan skema konseptual untuk databse yang tidak tergantung pada sistem manajemen database yang spesifik. Dalam perancangannya, penulis menggunakan metode bottom-up yang dimana perancangan dimulai dari pendefinisian atribut-atribut terlebih dahulu, setelah itu dilanjutkan dengan keterhubungannya beserta atribut-atributnya dimana pendefinisian tipe entity dari lebih rendah ke tipe yang lebih tinggi. Pada tahan awal, sesuai dengan kebutuhan pengguna dan proses bisnis. Atribut yang dibutuhkan diantaranya adalah :
1) RateCodeName
2) RateCodeDescription
9) PostingType
3) WeekendRateFlag
10) RoomCat
4) RateSeasonName
11) RomType
5) RateSeasonDescription
12) AdultRate
6) StartDate
13) ChildrenRate
7) EndDate
14) WeekendRate
8) TransCode
15) RateBaseCode
16) RateBaseDescription

Setelah didefinisikan atribut yang akan digunakan, maka dilakukan pembuatan entitas sebagai berikut :

1) RM22_RateCode : ID, RateCodeName, RateCodeDesc, WRate

2) RM22_RateSeason : ID, RateSeasonName, RateSeasonDesc, StartDate, EndDate

3) RM22_RateMaster : ID, TransCode, PostingType, RoomCat, RoomType, AdultRate, ChildRate, WeekendRate

4) RM15_RateBase : RBCode, RBDescrip

Sehingga dihasilkan skema konseptual yang dapat dilihat pada gambar 1 


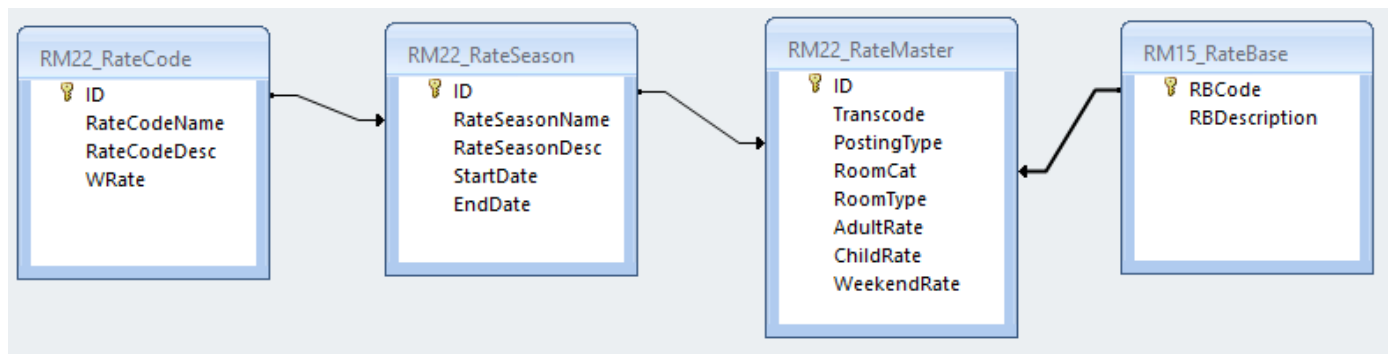

Gambar 1. Skema Konseptual

b. Skema Logika

Pada skema logika adalah model data relasional yang menggambarkan data dalam bentuk tabel-tabel yang mengandung tiga komponen inti yaitu :

1) Struktur data, data diorganisasi dalam bentuk tabel-tabel.

2) Manipulasi data, menggunakan SQL.

3) Integritas data, untuk spesifikasi aturan bisnis.

4) Relasi yang dihasilkan pada skema ini adalah tabel data dua dimensi.

Pada tahapan ini, terdapat penambahan pada masing-masing tabel sebagai berikut :

1) RM22_RateCode : RateCodeID (perubahan dari kolom ID dan sebagai primary key), WEnd1 (konfigurasi untuk menentukan hari pertama akhir pekan), WEnd2 (konfigurasi untuk menentukan hari kedua akhir pekan), beberapa kolom sebagai catatan aktifitas (CreatedOn, CreatedBy, UpdateBy, UpdateOn), dan IsActive (Penanda RateCode tersebut dapat digunakan atau tidak).

2) RM22_RateSeason: RateSeasonID (perubahan dari kolom ID dan sebagai primary key), beberapa kolom sebagai catatan aktifitas (CreatedOn, CreatedBy, UpdateBy, UpdateOn), dan IsActive (Penanda RateCode tersebut dapat digunakan atau tidak)

3) RM22_RateMaster : RateMasterID (perubahan dari kolom ID dan sebagai primary key), AdultRatePlus (penambahan biaya untuk tamu kedua dan seterusnya), AdultRateMaxPax (konfigurasi jumlah maksimal tamu yang dikenakan biaya tambahan), ChildRatePlus (penambahan biaya untuk tamu anak-anak kedua dan seterusnya), ChildRateMaxPax (konfigurasi jumlah maksimal tamu anak-anak yang dikenakan biaya tambahan). AdultWeekendRate (harga kamar untuk tamu pada akhir pekan), AdultWeekendRatePlus (penambahan biaya untuk tamu kedua dan seterusnya pada akhir pekan), ChildWeekendRate (harga kamar untuk tamu anak-anak pada akhir pekan), ChildWeekendRatePlus (penambahan biaya untuk tamu anak-anak kedua dan seterusnya pada akhir pekan).

Sehingga hasil dari penambahan kolom pada tahap ini dapat dilihat pada gambar 2

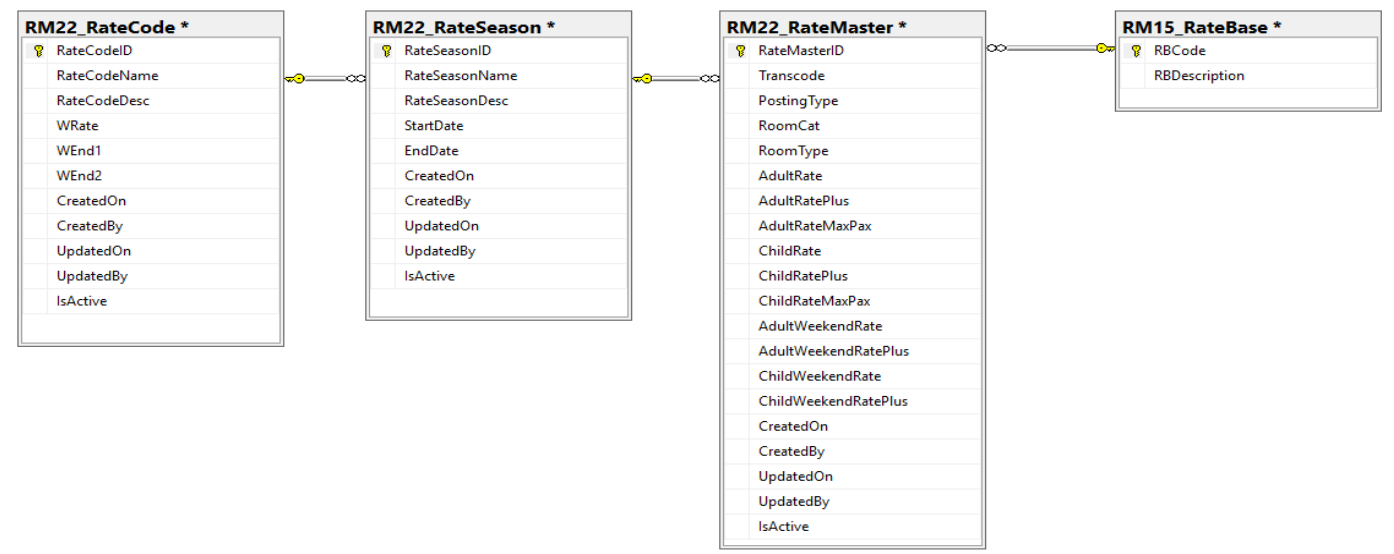

Gambar 2. Skema Logika 
c. Skema Fisik

Perancangan database secara fisik merupakan proses pemilihan struktur-struktur penyimpanan dan jalur-jalur akses pada file-file database untuk mencapai penampilan yang terbaik pada bermacam-macam aplikasi. Selama fase ini, dirancang spesifikasispesifikasi untuk database yang disimpan yang berhubungan dengan struktur-struktur penyimpanan fisik, penempatan record dan jalur akses. Sehingga dihasilkan skema fisik yang dapat dilihat pada gambar 3

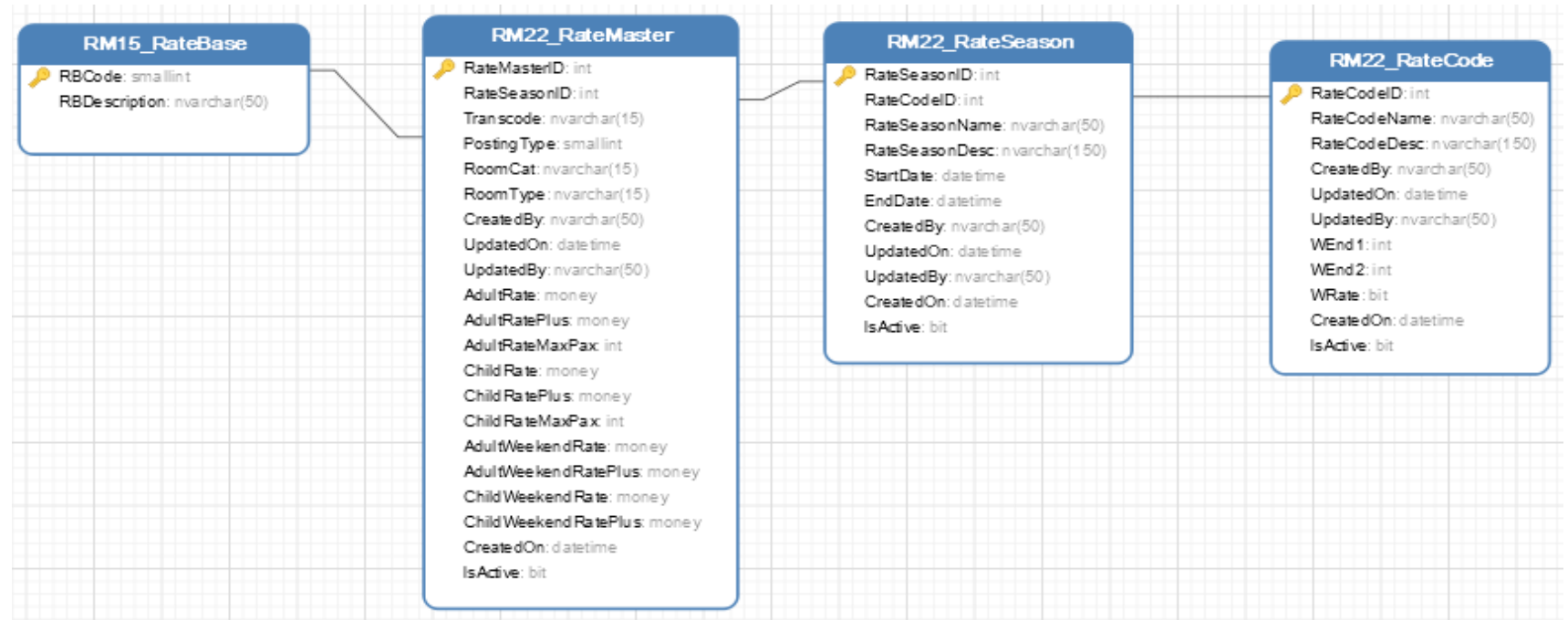

Gambar 3 Skema Fisik

5. Implementation and Deployment

a. Kebutuhan Sistem

Berdasarkan permasalahan yang telah ditemukan, maka diperlukannya untuk mendesain ulang database. Setelah dilakukannya desain ulang database, maka diperlukan juga perubahan dalam sisi aplikasi. Dalam perancangan perlu didefinisikan dalam beberapa diagram agar memudahkan dalam perancangan database dan cara kerja dari aplikasi, dapat di lihat pada use case, sebagaimana di tunjukan pada gambar 4

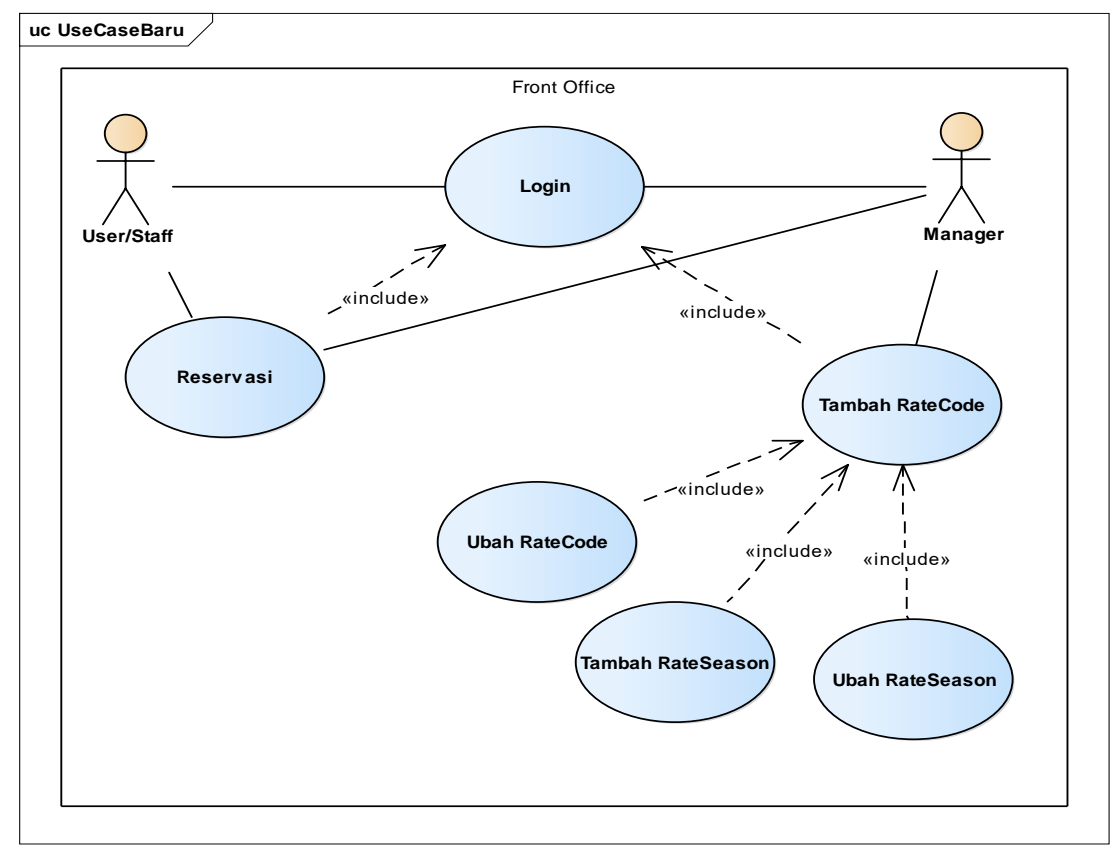

Gambar 4 .Use Case Diagram 
Secara garis besar, sistem berjalan saat ini, pengguna aplikasi dibagi menjadi dua, yaitu pengguna biasa yang memiliki hak akses login dan membuat reservasi, sedangkan pengguna dengan tingkatan manager bisa mengakses login, reservasi dan Rate Code management.

b. Antar Muka system

1. Pembuatan Rate Code

Pada pembuatan Rate Code baru pengguna mengisi data Nama Rate Code, Deskripsi Rate Code, indikator akhir pekan, dan menentukan hari apa saja akhir pekan itu. Tampilan aplikasi dapat dilihat pada gambar 5

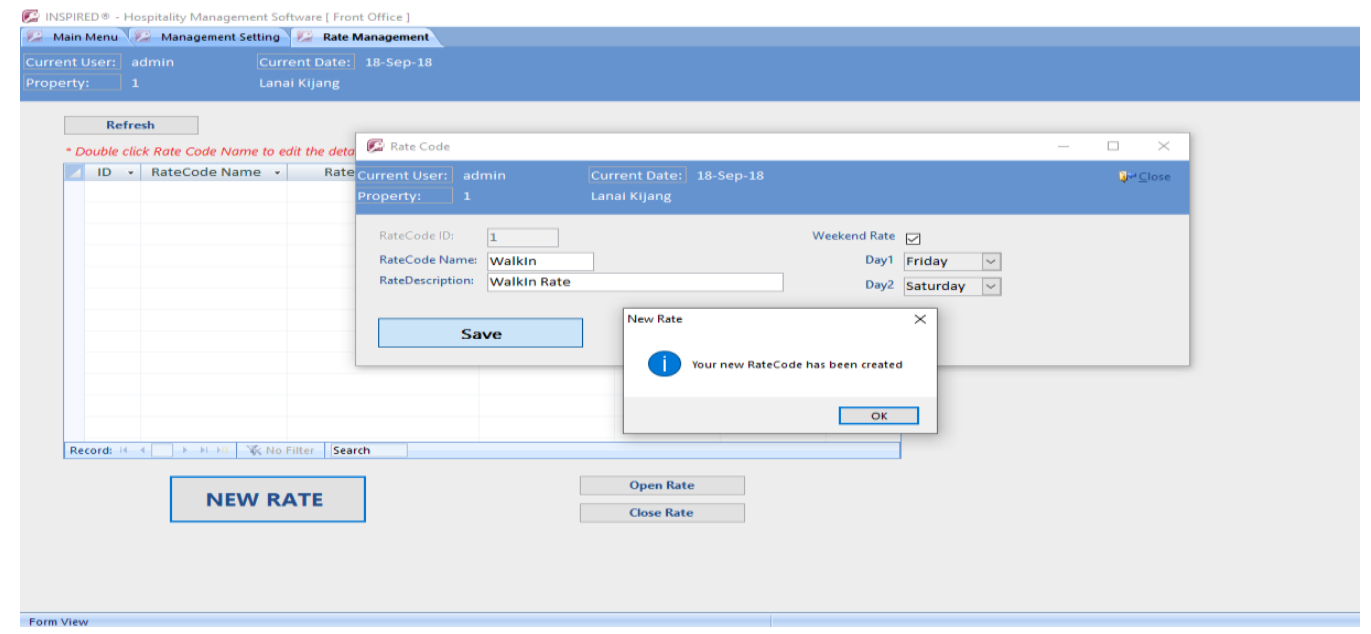

Gambar 5 . Pembuatan Rate Code melalui Aplikasi

2. Pembuatan Rate Season

Pada pembuatan Rate Season baru pengguna mengisi data Nama Rate Season, Deskripsi Rate Season, tanggal berlaku, dan melengkapi harga kamar berdasarkan kategori masing-masing. Tampilan aplikasi dapat dilihat pada gambar 6

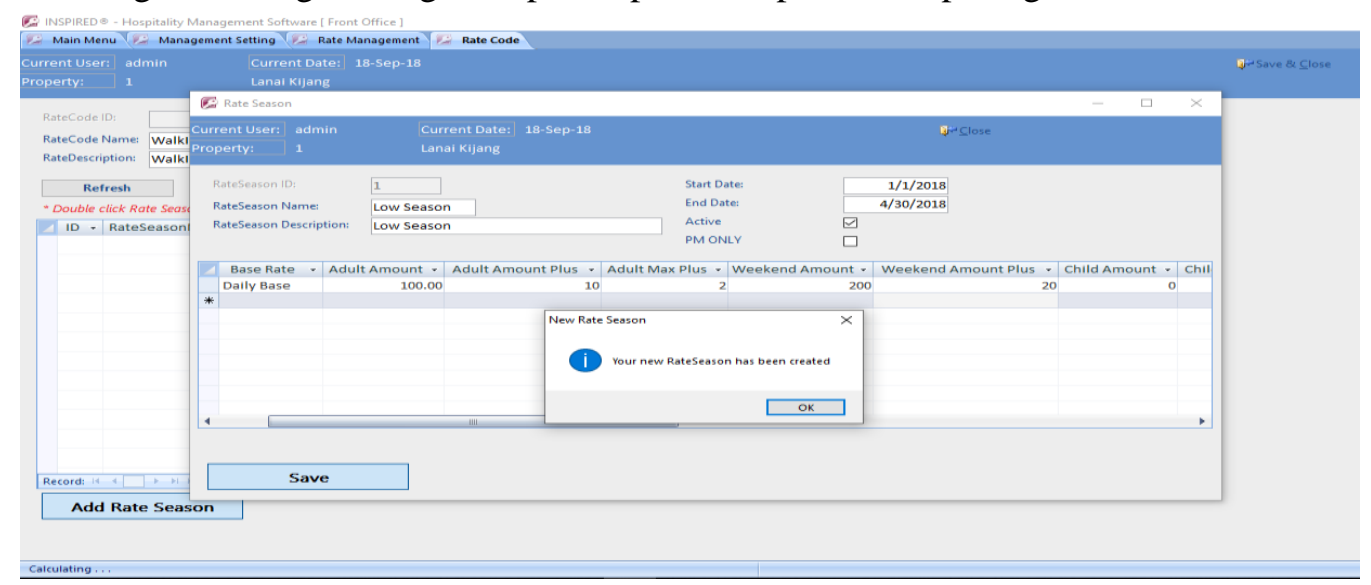

Gambar 6 Pembuatan Rate Season melalui Aplikasi

3. Mengubah Rate Season

Pada langkah mengubah Rate Season, pengguna memilih data Rate Season yang akan diubah kemudian melengkapi harga kamar berdasarkan kategori masing-masing yang ingin diubah nilainya. Tampilan aplikasi dapat dilihat pada gambar 7 


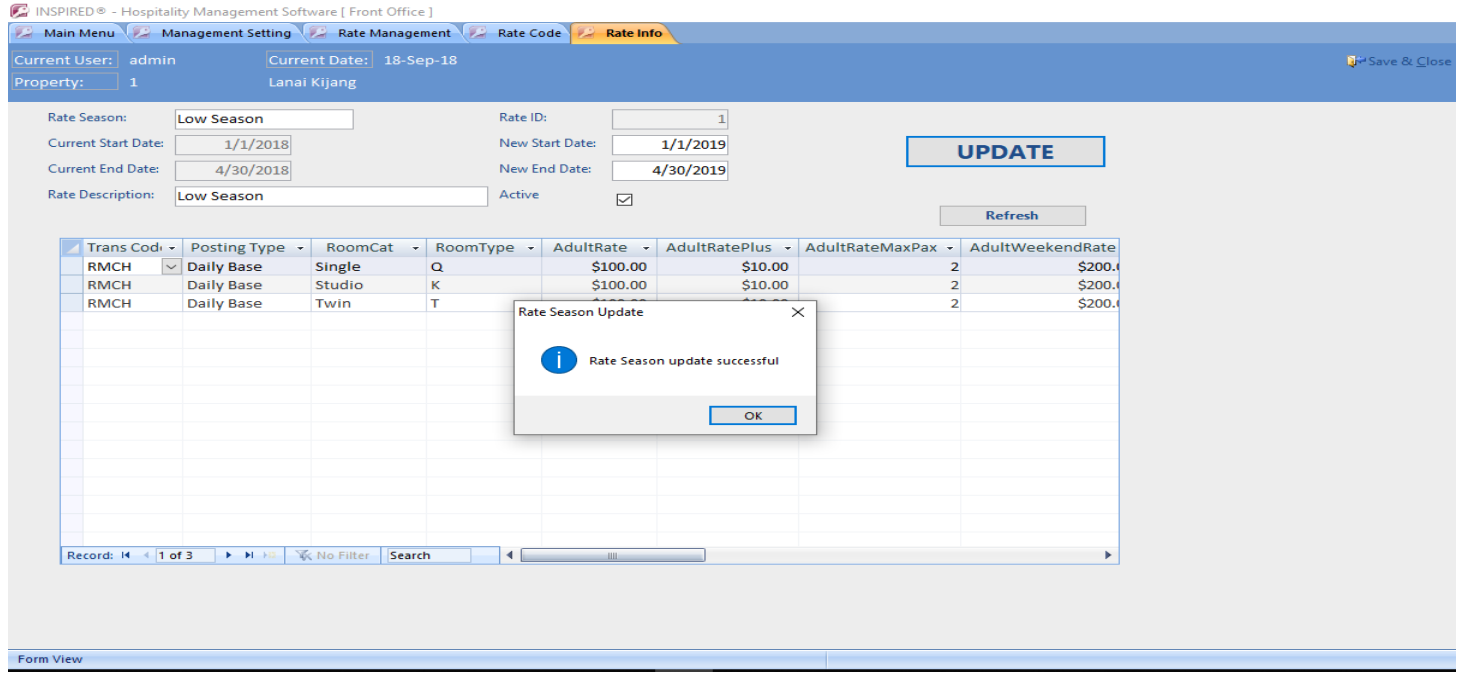

Gambar 7 Mengubah Rate Season melalui Aplikasi

4. Mengubah Rate Code

Pada langkah mengubah Rate Code, pengguna memilih data Rate Code yang akan diubah kemudian melengkapi informasi yang ingin diubah nilainya. Tampilan aplikasi dapat dilihat pada gambar 8

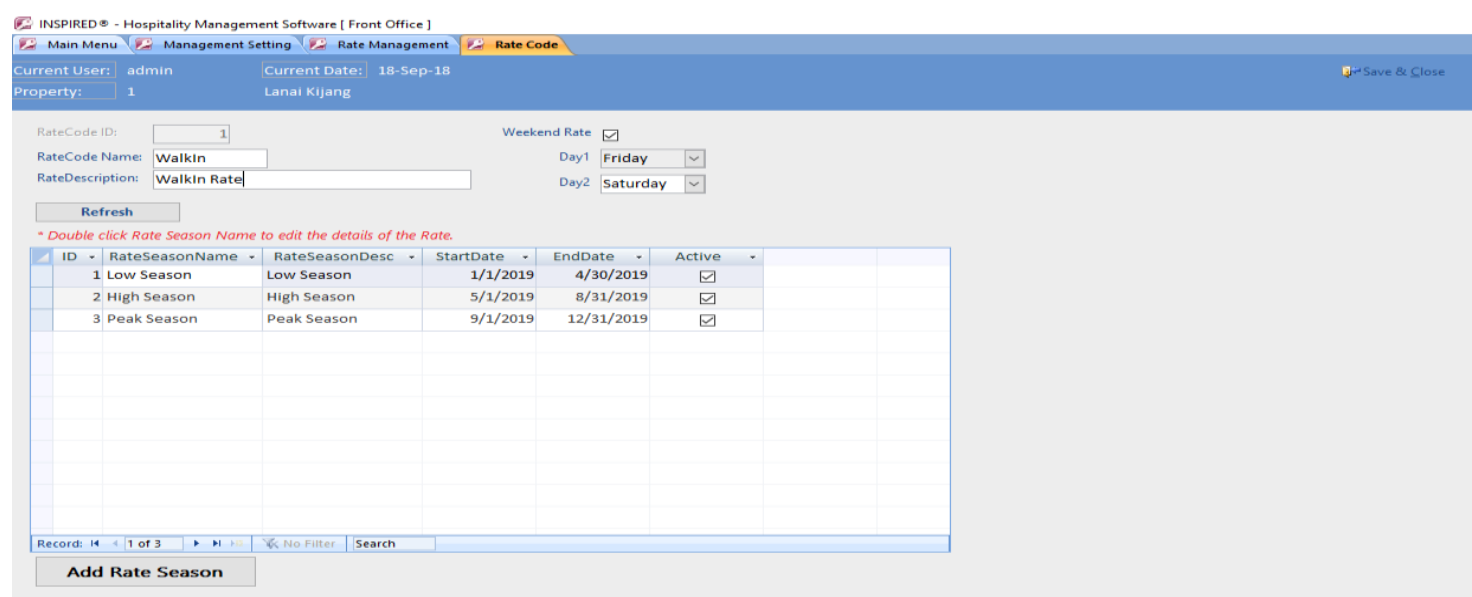

Gambar 8 Mengubah Rate Code Melalui Aplikasi

5. Pembuatan Reservasi

Pada langkah membuat reservasi, pengguna mengisi informasi tamu dilanjutkan memilih rate code. Tampilan aplikasi dapat dilihat pada gambar 9 


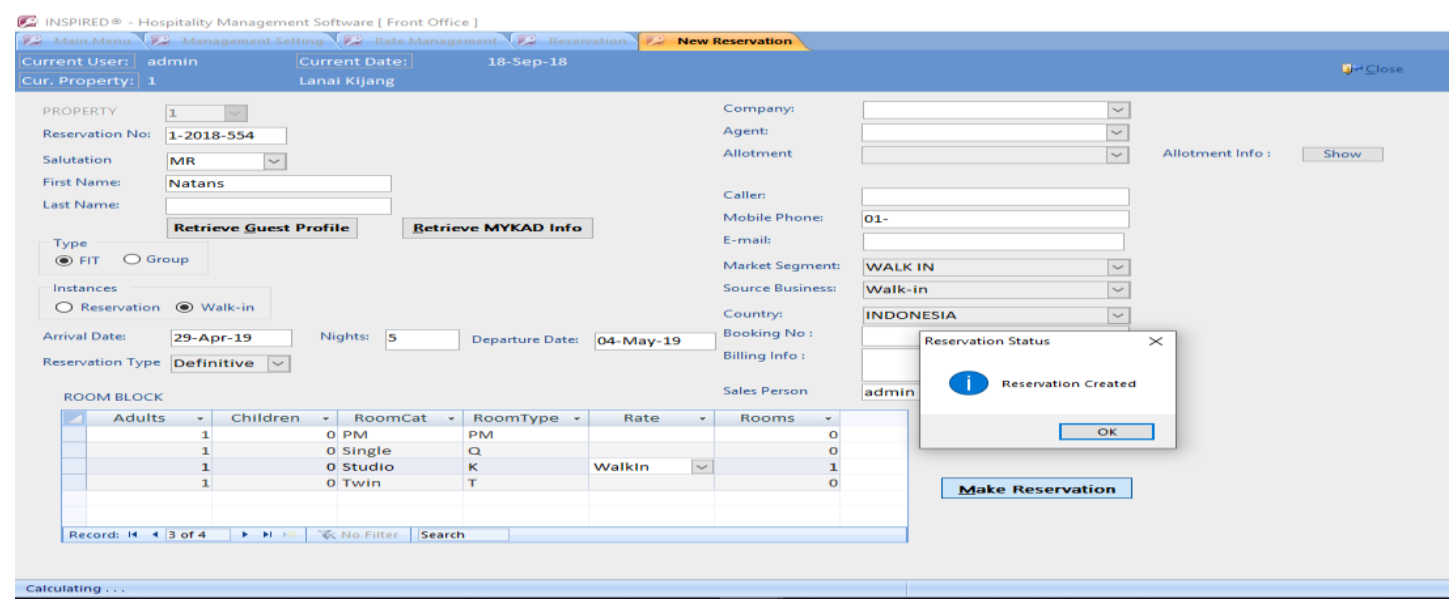

Gambar 9 Pembuatan Reservasi melalui Aplikasi

6. Jadwal posting Room Night Reservasi

Untuk memastikan harga kamar sudah sesuai dengan yang diinginkan, maka dilakukan pengecekan pada jadwal pemasangan harga kamar berdasarkan durasi tanggal tamu menginap. Tampilan aplikasi dapat dilihat pada gambar 10

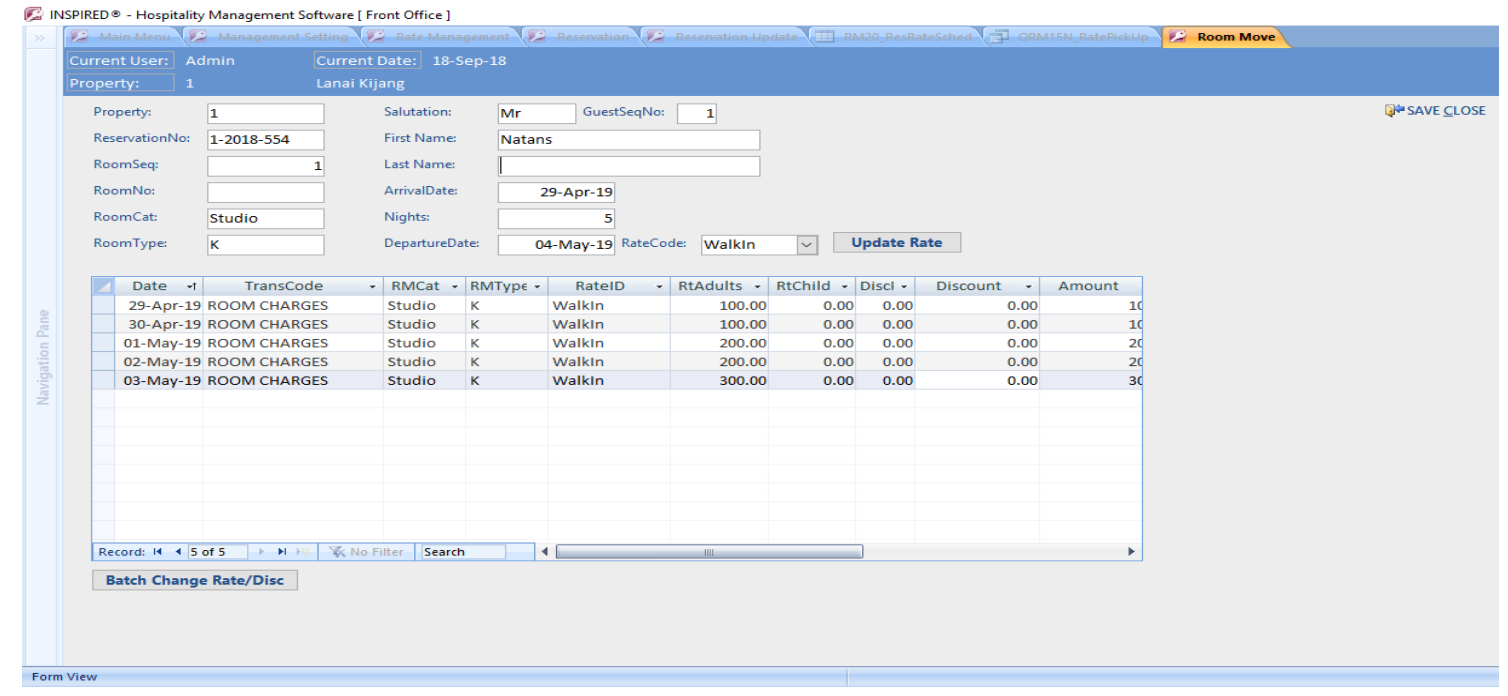

Gambar 10 . Jadwal posting Room Night Reservasi

B. Pembuktian Efisiensi Prosentase

Untuk membuktikan bahwa desain ulang database dengan metode bottom-up lebih efektif daripada database sebelumnya, maka akan dibuktikan dari efisiensi prosentase pada total byte yang dikelola, record yang dikelola, penggunaan ruang yang digunakan, jumlah tabel yang diproses, waktu dan record yang dihasilkan. Informasi untuk pemakaian ruang data untuk database sebelum dilakukannya desain ulang dapat dilihat pada tabel 4 
Tabel 4 . Tabel pada Database Lama

\begin{tabular}{|c|c|c|c|}
\hline \multicolumn{1}{|c|}{ Nama Tabel } & Penggunaan Ruang (KByte) & Jumlah Record & $\begin{array}{c}\text { Total } \\
\text { (Kbyte) }\end{array}$ \\
\hline RM15_RateMaster & 40 & 27 & 40 \\
\hline RM15_RateMasterSub & 176 & 106 & 224 \\
\hline RM15_RateBase & 32 & 5 & 32 \\
\hline TOTAL & $\mathbf{2 4 8}$ & $\mathbf{1 3 8}$ & $\mathbf{2 9 6}$ \\
\hline
\end{tabular}

Berikut informasi pemakaian ruang data untuk database setelah dilakukannya desain ulang menggunakan metode bottom-up dapat dilihat pada tabel 5

Tabel 5. Tabel pada Database Setelah desain ulang

\begin{tabular}{|c|c|c|c|}
\hline Nama Tabel & Penggunaan Ruang (KByte) & Jumlah Record & $\begin{array}{c}\text { Total } \\
\text { (Kbyte) }\end{array}$ \\
\hline RM22_RateCode & 16 & 2 & 72 \\
\hline RM22_RateSeason & 16 & 24 & 72 \\
\hline RM22_RateMaster & 32 & 72 & 72 \\
\hline RM15_RateBase & 32 & 5 & 32 \\
\hline TOTAL & $\mathbf{9 6}$ & $\mathbf{1 0 3}$ & $\mathbf{2 4 8}$ \\
\hline
\end{tabular}

Kemudian dilakukan penghitungan dengan persentase efisiensi dengan rumus :

Prosentase kenaikan $=($ data lama - data baru $) /$ data baru $* 100)$

Maka dari itu, dihasilkan perhitungan yang dapat dilihat pada tabel 6

Tabel 6 Prosentase Kenaikan

\begin{tabular}{|l|r|r|r|}
\hline & Penggunaan Ruang (KByte) & Jumlah Record & Total (Kbyte) \\
\hline Total Database Lama & 248 & 138 & 296 \\
\hline Total Database Baru & 96 & 103 & 248 \\
\hline Prosentase Kenaikan & 158.33 & 33.98 & 19.35 \\
\hline
\end{tabular}

\section{SIMPULAN DAN SARAN}

Berdasarkan pada hasil penelitian yang telah dilakukan dapat ditarik beberapa kesimpulan sebagai berikut:

1. Membuat satu kode harga namun memiliki harga yang berbeda dalam periode tertentu dapat dicapai dengan menambahkan tabel rate season dan mendesain ulang tabel rate code.

2. Membantu pengguna agar tidak perlu melakukan pemilihan ratecode secara manual sesuai dengan tanggal reservasi setelah ditambahkan rate season yang berbeda berdasarkan periode tertentu dalam satu rate code

3. Metode bottom-up lebih cocok untuk mendesain database dalam skala kecil yang memiliki atribut sedikit, sedangkan untuk melakukan desain ulang database pada keseluruhan sistem front office InspiredHMS lebih tepat menggunakan metode top-down 


\section{DAFTAR RUJUKAN}

Calero, C., Piatiini, M., Pascual, C., and Serrano, M.A. (2001). "Towards Data Warehouse Quality Metrics". Interlaken: Proceedings of the 3rd Intl. Workshop on Design and Management of Data Warehouses (DMDW'2001).

Connolly, Thomas., Carolyn, Begg. (2005) "Database System: A Practical Approach to Design, Implementation, and Management, 4th edition". Hamilton: Addison-Wesley.

Ponniah, Paulraj. (2007). “Data Modeling Fundamental”. New Jersey: John Wiley \& Sons Inc. 